\title{
Ferrocene triphenylmethyl radical donor-acceptor compounds. Towards the development of multifunctional molecular switches
}

\author{
Christian Sporer, ${ }^{a}$ Imma Ratera, ${ }^{a}$ Klaus Wurst, ${ }^{b}$ J. Vidal-Gancedo, ${ }^{a}$ Daniel Ruiz-Molina, ${ }^{a}$ \\ Concepció Rovira, ${ }^{a}$ and Jaume Veciana* ${ }^{a}$ \\ ${ }^{a}$ Institut de Ciència de Materials de Barcelona (CSIC), Campus Universitari de Bellaterra \\ 08193, Cerdanyola, Spain \\ ${ }^{b}$ Institut für Allgemeine, Anorganische und Theoretische Chemie, Universität Innsbruck, Innrain \\ 52a, A-6020, Innsbruck, Austria \\ E-mail:vecianaj@icmab.es
}
Dedicated to Prof. Jose Elguero on his $70^{\text {th }}$ anniversary and Prof. Pedro Molina on his $60^{\text {th }}$ anniversary

(received 15 Dec 04; accepted 10 Feb 05; published on the web 25 Feb 05)

\begin{abstract}
Ferrocene-substituted polychlorinated triphenylmethyl radical (1) is a neutral paramagnetic donor-acceptor dyad that exhibits an intramolecular charge-transfer band in the near-infrared (NIR) region. It can be converted reversibly into its diamagnetic precursors $\mathbf{1}^{-}$and $\mathbf{1 H}$ by chemical reduction and subsequent acid/base reaction or oxidized to the ferrocenium diradical $\mathbf{1}^{+}$; each interconversion being accompanied with drastic changes of the optical properties. The new synthetic route described here allows the isolation of $\mathrm{K}^{+}(18-C r o w n-6)[1]^{-}$salt in crystalline form, making possible the X-ray crystal structure determination. Because all derivatives exhibit extraordinary chemical and thermal stability, both in solution and in the solid state, radical 1 may be used as a model compound for the development of new multifunctional molecular switches.
\end{abstract}

Keywords: Triphenylmethyl radicals, ferrocene, intramolecular electron-transfer, molecular switches

\section{Introduction}

Polychlorinated triphenylmethyl radicals (PTM), have exceptional chemical and thermal stability owing to an effective steric shielding of their open-shell centers by six bulky chlorine atoms, ${ }^{1}$ and are ideal candidates to be incorporated into compounds exhibiting magnetic properties. ${ }^{2}$ Also, these compounds give non-linear optical responses owing to their octupolar nature and show fully reversible redox properties with low reduction potentials. Such characteristics allow 
them to be switched electrochemically between optically and magnetically active or non-active states. $^{3,4}$

We are interested in obtaining new PTM radicals substituted with electron-donor active groups, like ferrocene, because for such donor-acceptor dyads interesting optical and magnetic properties were expected. Therefore we have synthesized and studied a series of ferrocenesubstituted PTM radicals 1-3, which show distinct ferrocene- donor strengths and different conjugated bridges. ${ }^{5-7}$
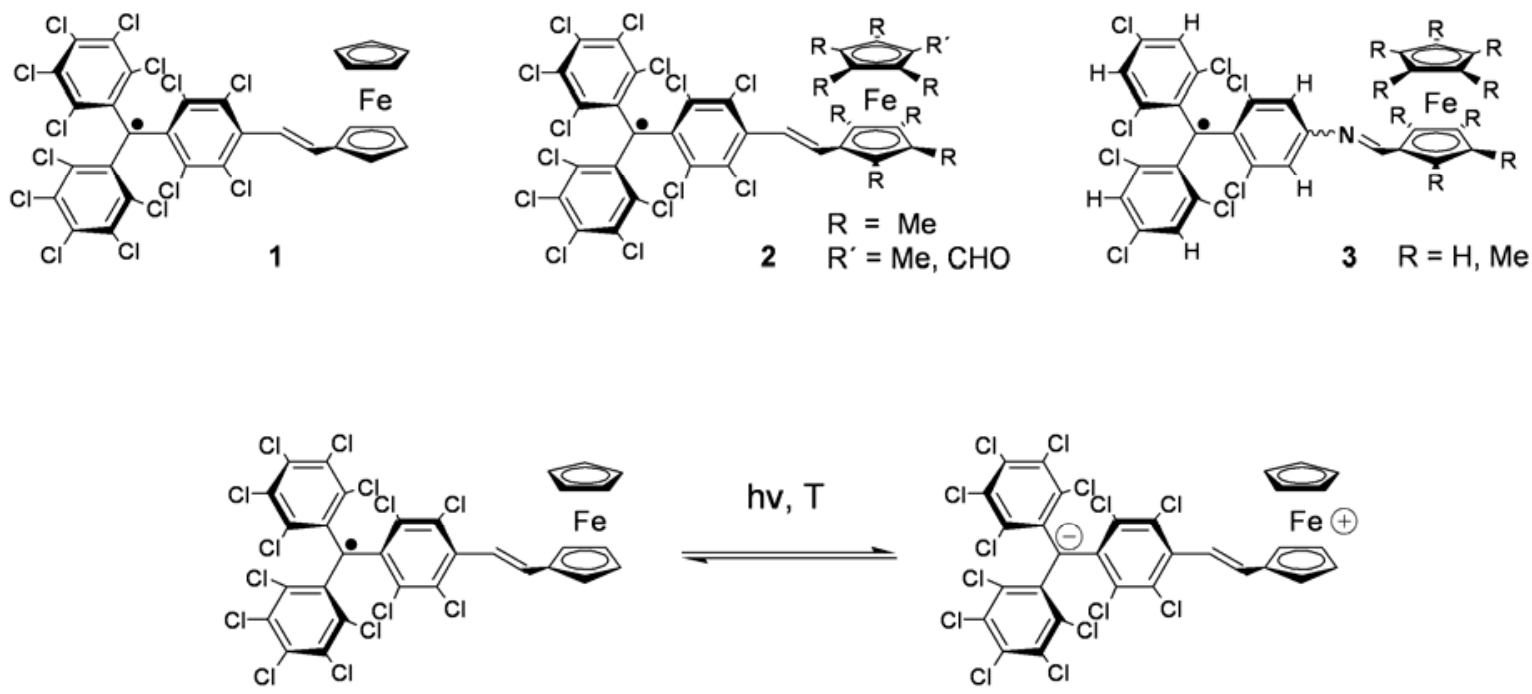

Figure 1. PTM radicals substituted with different ferrocene donors can undergo intramolecular electron transfer.

In fact, it was found that all these compounds can undergo intramolecular electron transfer (IET) from the ferrocene donor to the PTM acceptor moiety, resulting in intervalence band absorptions in the near-infrared region of the electronic spectra. This IET can be induced by light- irradiation, and in radical 1 also by a change of temperature, exhibiting for this compound a temperature-dependent valence tautomerism. ${ }^{5 a}$ Furthermore, such a kind of donor-acceptor dyads show interesting second-order non-linear optical responses. ${ }^{6 \mathrm{a}, 7 \mathrm{c}}$ Besides being just a simple electron donor group, the electroactive ferrocene can also act as an switching element in these donor-acceptor dyads since the oxidation to the ferrocenium cation brings the opportunity to modulate the optical properties of the molecules, and at the same time introducing an additional paramagnetic center. ${ }^{8}$ Recently, we have reported on the nonamethylferrocene- substituted PTM radical $2\left(\mathrm{R}^{\prime}=\mathrm{Me}\right)$ where switching of the optical and magnetic properties was achieved by an electrochemical variation of the oxidation states of the radical in solution. ${ }^{6 a}$ However, a similar switching behavior has never been investigated for the ferrocene PTM radical, 1. 
In this work we demonstrate the ability of radical $\mathbf{1}$ to act as a multistate/multiproperty molecular switching device whose distinct states can be interconverted reversibly by acid/base and redox reactions exhibiting, completely different optical and magnetic properties.

\section{Results and Discussion}

\section{Synthesis}

While the one-pot synthesis of radical $\mathbf{1}$ has been described earlier, we report here a new synthetic route that allows the isolation of a salt derived from the anion $\mathbf{1}^{-}$, in the solid state, and its X-ray crystal structure determination. This new route uses $\mathbf{1 H}$ as the starting compound. The synthesis of the precursor $\mathbf{1 H}$ involves a Wittig reaction between ferrocene monocarboxaldehyde and the appropriate perchlorinated triphenylmethyl phosphonium bromide, as has already been published. $^{5 b, c}$ This reaction is strongly stereoselective since it yields the trans- ethylene-bridged isomer almost exclusively, as confirmed by NMR spectroscopy. After chromatographic workup compound $\mathbf{1 H}$ was obtained in $83 \%$ yield.
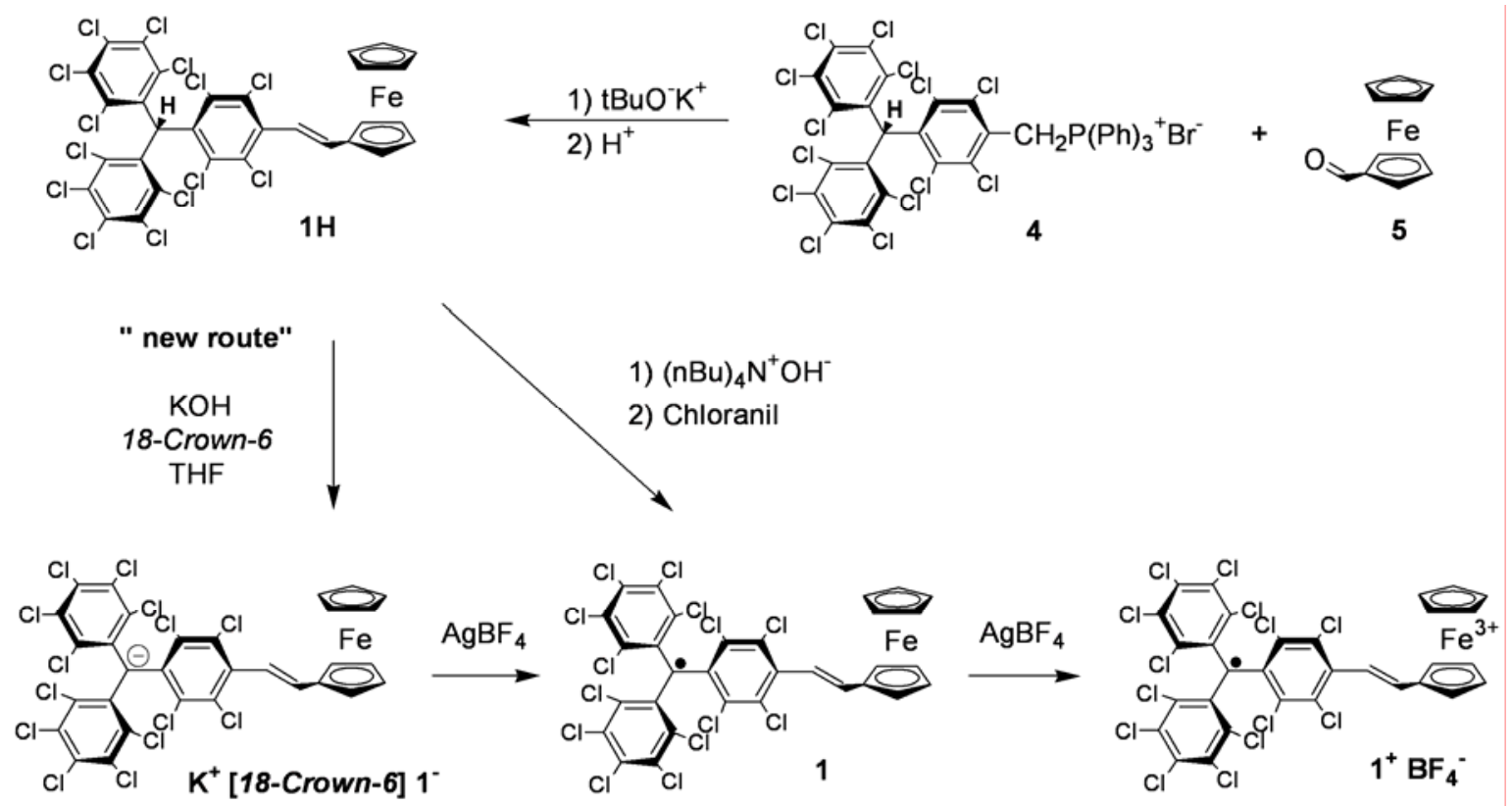

\section{Scheme 1}

While in the synthetic route reported earlier the triphenylmethane precursor $\mathbf{1 H}$ was deprotonated and oxidized directly to radical $\mathbf{1}$, without isolation of the intermediate anion $\mathbf{1}^{-}$, the new methodology described here gives access to the $\mathrm{K}^{+}(18$-Crown- 6$)$ salt of the triphenylmethide $\mathbf{1}^{-}$in good yield, allowing its detailed characterization. The $\mathrm{K}^{+}(18-C r o w n-6)$ $[\mathbf{1}]^{-}$salt crystallizes easily by slow diffusion of $n$-hexane into a $\mathrm{CH}_{2} \mathrm{Cl}_{2}$ solution of the salt, 
forming crystals suitable for an X-ray crystal structure determination. In the solid state, $\mathrm{K}^{+}(18$ Crown-6) $[\mathbf{1}]^{-}$forms a 1-dimensional coordination polymer by coordination of $\mathrm{Cl}$ atoms in the anion sub-units with the potassium linking alternating carbanions and cationic moieties. Remarkably, the ethylene bridge of $\mathbf{1}^{-}$keeps its trans-configuration and the mean plane defined by the carbon atoms $\mathrm{C}(10)-\mathrm{C}(13)$ shows almost no deviation from coplanarity with the ferrocene $\mathrm{Cp}$-ring mean plane $\left(2^{\circ}\right)$. In contrast to the solid state structures of radicals 1 and $2\left(\mathrm{R}^{\prime}=\mathrm{Me}\right)$, which have already been described, ${ }^{5 \mathrm{a}, 6 \mathrm{a}}$ the ethylene bridge shows no positional disorder and the bond lengths are in the expected range for conjugated single- and double bonds $(\mathrm{C}(10)-\mathrm{C}(11)$ : 1.461(4) $\AA, C(11)-C(12): 1.328(4) \AA$ and $C(12)-C(13): 1.477(4) \AA)$. On the other hand, the tetrachlorophenyl moiety of the radical unit deviates from coplanarity with the ethylene group by about $41^{\circ}$, probably owing to the steric repulsion between the bulky chlorine atoms and the $\mathrm{H}$ atoms of the bridging group.

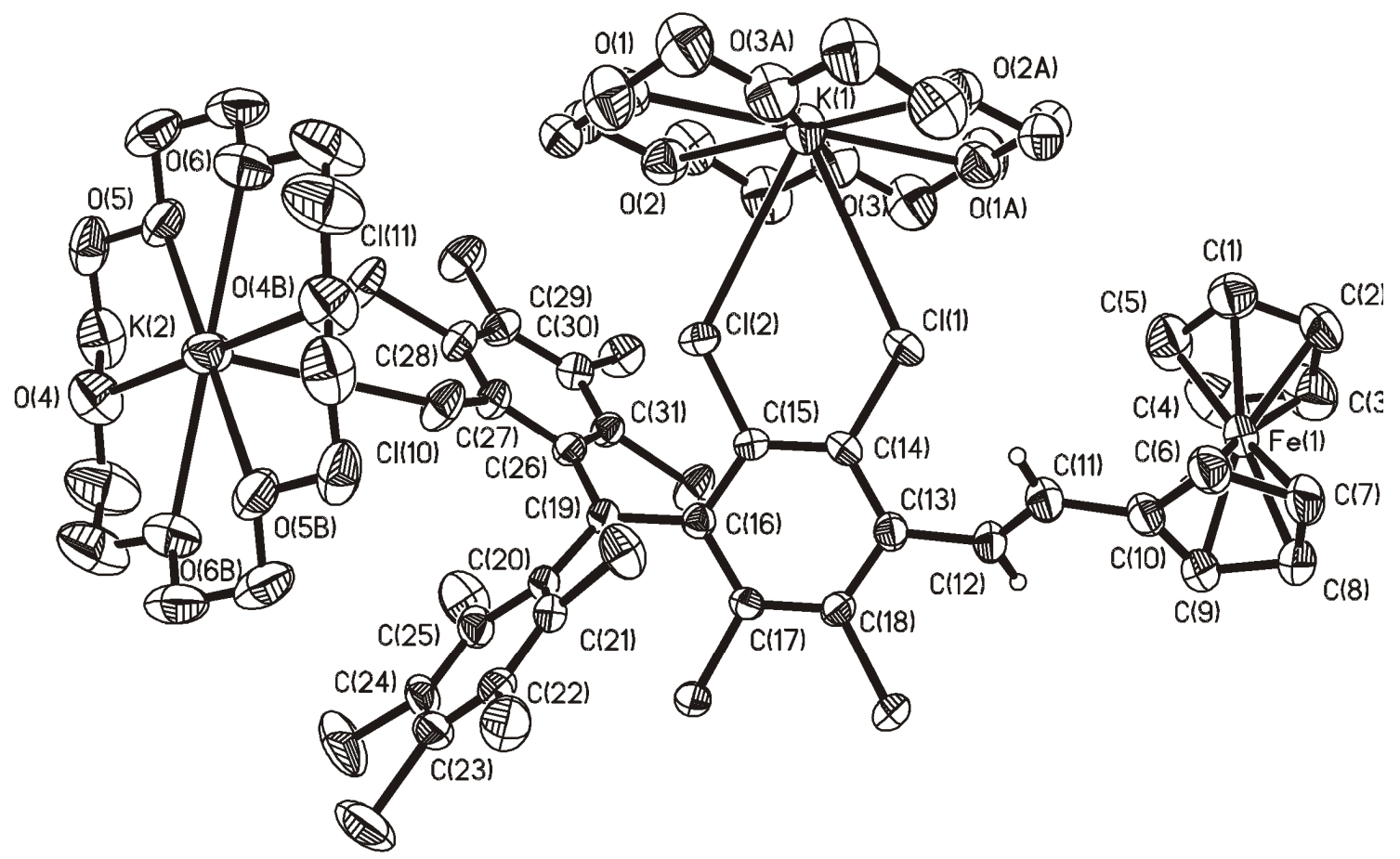

Figure 2. View of the asymmetric unit of $\mathrm{K}^{+}(18 \text {-Crown-6) [1] }]^{-}$. Thermal ellipsoids are shown at the $50 \%$ probability level. Both $\mathrm{K}^{+}(18$-Crown- 6$)$ moieties are shown completely. The disordered solvent molecule $\mathrm{CH}_{2} \mathrm{Cl}_{2}$ and all hydrogen atoms, except those on the ethylene moiety, are omitted for the sake of clarity.

In the triphenylmethyl anion sub-unit, each of the three phenyl rings is twisted in the same sense by about $43^{\circ}$ from the mean plane formed by the central $s p^{2}$ - hybridized carbon $C(19)$ and the three aromatic carbon atoms $\mathrm{C}(16), \mathrm{C}(20)$ and $\mathrm{C}(26)$. Although the propeller-like arrangement adopted by the anionic unit allows the molecule to exist in two enantiomeric forms, 
this fact does not lead to macroscopic chirality in the crystal structure, owing to the occurrence of equal amounts of both enantiomers in the unit cell. In addition, there are two crystallographically non-equivalent $\mathrm{K}^{+}(18$-Crown-6) moieties in the crystal structure, in which each potassium cation coordinates additionally to four chlorine atoms of the aromatic groups in the anionic part of the molecule, with average potassium-chlorine distances between 3.51-3.73 $\AA$.

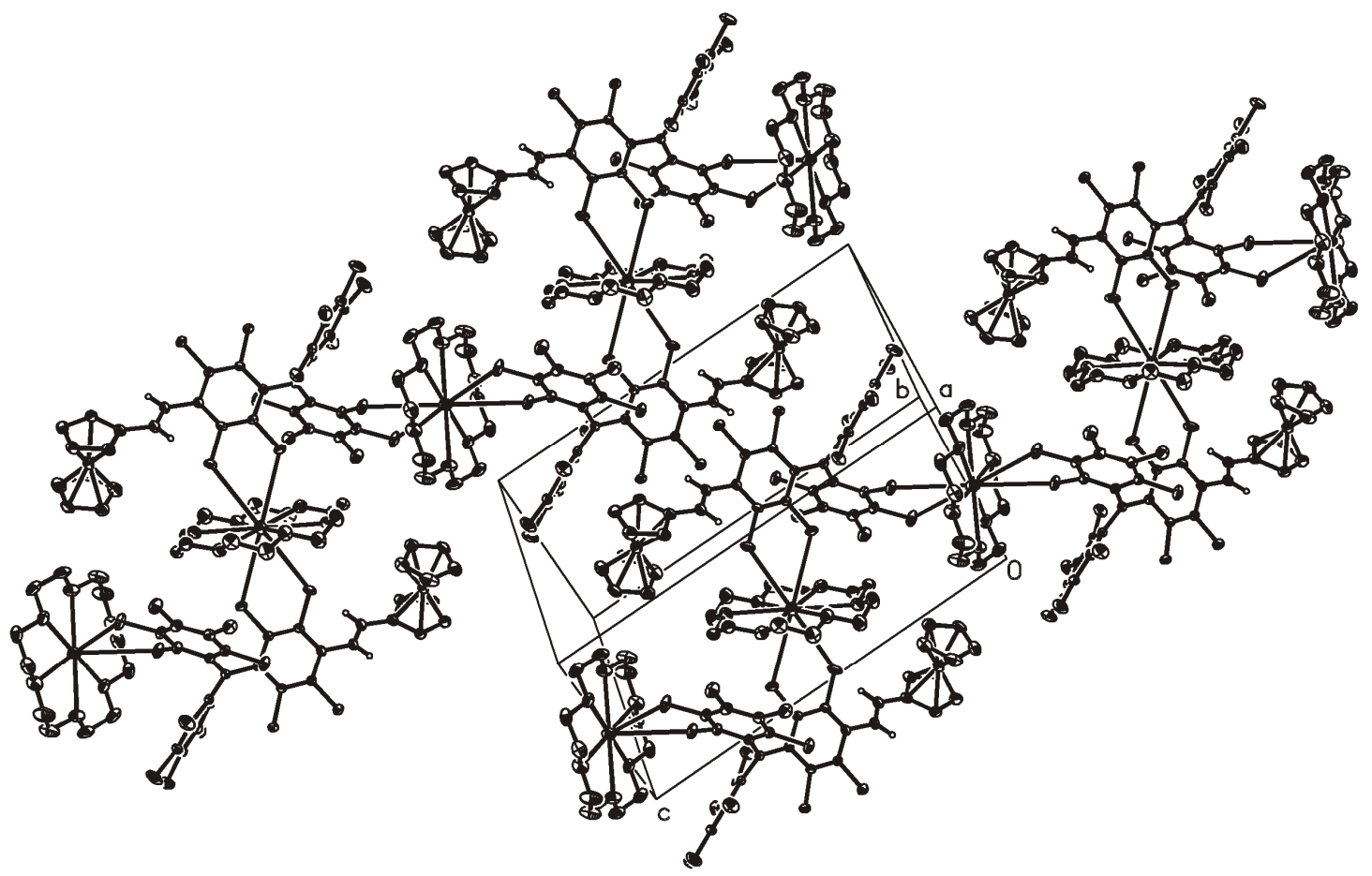

Figure 3. Crystal structure of $\mathrm{K}^{+}(18-\text { Crown-6) [1] }]^{-}$. View of the zig-zag polymeric chain along the $c$-axis.

\section{Optical properties}

The most striking difference between the triphenylmethane derivative $\mathbf{1 H}$, the anion $\mathbf{1}^{-}$, the radical $\mathbf{1}$ and the cationic diradical $\mathbf{1}^{+}$, both in solution and in the solid state, is their different color. While compound $\mathbf{1 H}$ only shows a weak absorption above $400 \mathrm{~nm}$, which is responsible for its pale pink color, corresponding to ferrocene MLCT absorptions centered around $472 \mathrm{~nm}$, the violet organic salt $\mathbf{1}^{-}$exhibits an intense absorption band at $534 \mathrm{~nm}$, which is typical of polychlorotriphenylmethanides. By contrast, the reddish brown radical 1 exhibits an intense absorption band at $387 \mathrm{~nm}$ and weaker bands centered at 570 and $638 \mathrm{~nm}$, which can be assigned to the radical character of the triphenylmethyl unit. The absorption band observed at $444 \mathrm{~nm}$ can be ascribed to ferrocene MLCT transitions. Most important, a weak and broad absorption can be observed at $968 \mathrm{~nm}$. This band can be ascribed to a charge-transfer band associated with the intramolecular electron transfer (IET) from the ferrocene unit (donor) to the radical unit, that acts as an electron acceptor. The concentration-dependence of this band follows the Lambert-Beer 
law, a fact that confirms its intramolecular nature. Furthermore, this intramolecular chargetransfer band shows a strong solvent-dependence with a positive solvatochromism - a shift of the absorption maximum to higher wavelength with an increasing the polarity of the solvent. Similar charge-transfer bands have also been observed for radicals 2 and 3, the exact location of the absorption maximum being strongly dependent on the ferrocene donor strength. For radical 1, such a solvatochromic behavior, as well as the structural and electronic similarities to radicals 2 and 3, also let us expect a second-order non-linear optic response. Experiments in this direction are currently on the way. The UV-Vis spectrum of the yellowish cation diradical $\mathbf{1}^{+}$still exhibits the typical radical absorption at $386 \mathrm{~nm}$ with almost the same intensity as for radical 1 itself. As expected, $\mathbf{1}^{+}$does not exhibit any charge-transfer band in the near infrared region, because the oxidation of the ferrocene moiety destroys its donor capability.
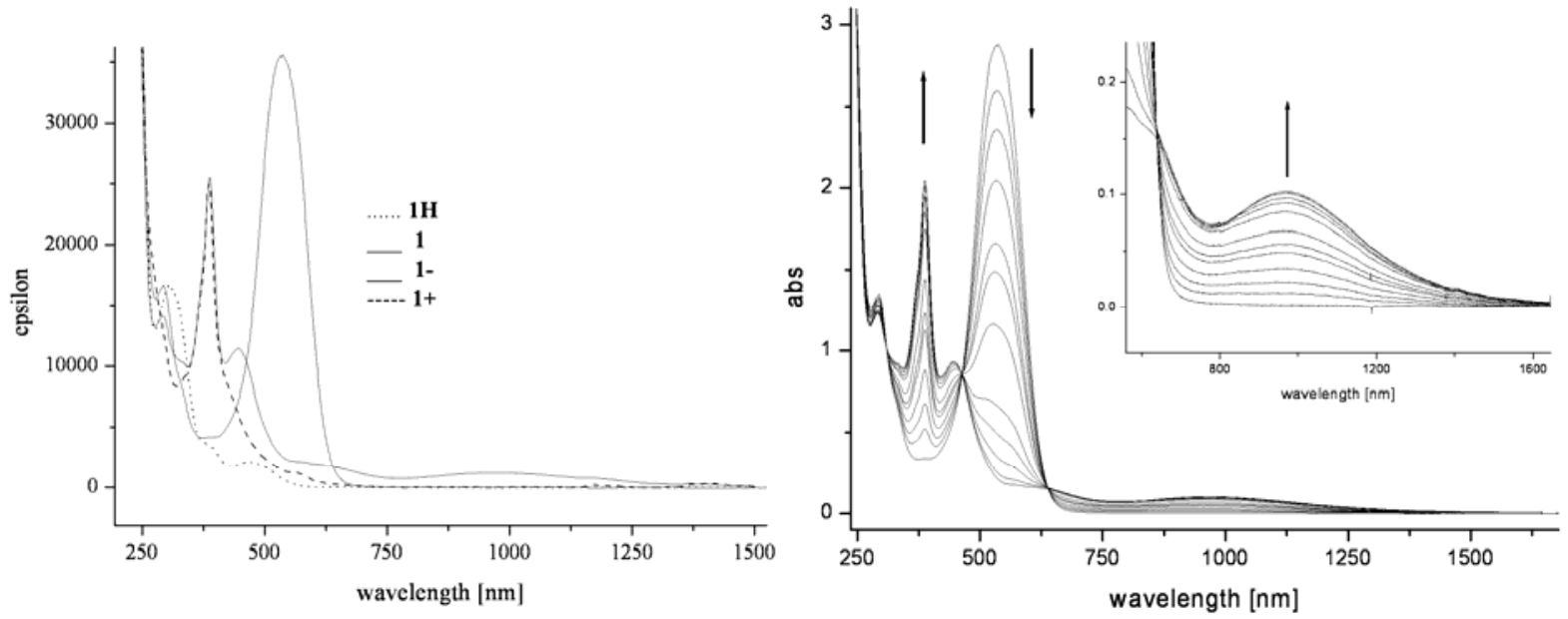

Figure 4. Left: UV-Vis-near-IR spectra of precursor $\mathbf{1 H}$, anion $\mathbf{1}^{-}$, radical $\mathbf{1}$ and the chemically generated diradical cation $\mathbf{1}^{+}$recorded in THF. Right: development of the UV-Vis-near-IR spectra of radical $\mathbf{1}$ on oxidation of anion $\mathbf{1}^{-}$by addition of a controlled amount of $\mathrm{AgBF}_{4}$ in THF. The inset shows the intervalence band with maximum absorption at $968 \mathrm{~nm}$. Trends of intensity changes are shown for a few particular bands with arrows pointing up or down.

\section{Magnetic properties}

The X-band EPR isotropic spectra of radicals $\mathbf{1}^{5 \mathrm{c}}$ and $\mathbf{1}^{+}$were obtained in toluene- $\mathrm{CH}_{2} \mathrm{Cl}_{2}(1: 1)$. They show several partially overlapped lines corresponding to the coupling of the unpaired electron with the different nuclei with non-zero magnetic moments; i.e. with ${ }^{1} \mathrm{H}$ and the naturally abundant ${ }^{13} \mathrm{C}$ isotope at the $\alpha$ - and aromatic positions. Computer simulation of the EPR spectra provides the isotropic $g$-value $\left(g_{\text {iso }}\right)$ and those of the hyperfine coupling constants $\left(a_{i}\right)$. The $g_{\text {iso }}$ value for radical 1 was 2.0035, whereas the isotropic hyperfine coupling constant values with the $\mathrm{H}$ atoms of the ethylene moieties and with some of the carbon nuclei of the triphenylmethyl unit show the usual values for this kind of radicals; i.e, $a_{1}\left({ }^{1} \mathrm{H}\right) \approx 1.8 \mathrm{G}(1 \mathrm{H}), a_{2}\left({ }^{1} \mathrm{H}\right) \approx 0.7 \mathrm{G}(1 \mathrm{H})$ and $a_{1}\left({ }^{13} \mathrm{C}\right) \approx 29.8 \mathrm{G}\left(1 \mathrm{C}_{\alpha}\right), a_{2}\left({ }^{13} \mathrm{C}\right) \approx 12.0 \mathrm{G}\left(3 \mathrm{C}_{\text {para }}\right), a_{3}\left({ }^{13} \mathrm{C}\right) \approx 10.5 \mathrm{G}\left(6 \mathrm{C}_{\text {ortho }}\right)$. The spectra of 
radical 1 and biradical $\mathbf{1}^{+}$show very similar characteristics, indicating that the two electrons in $\mathbf{1}^{+}$ have a very small magnetic interaction, with an exchange coupling constant, $J$, very much smaller than the hyperfine coupling constant $\left(a_{\mathrm{i}}\right)$ with the magnetically active nuclei; i.e., $J<<a_{\mathrm{i}}$. So, the ground state of $\mathbf{1}^{+}$is described by a value of $S=2 \cdot 1 / 2$

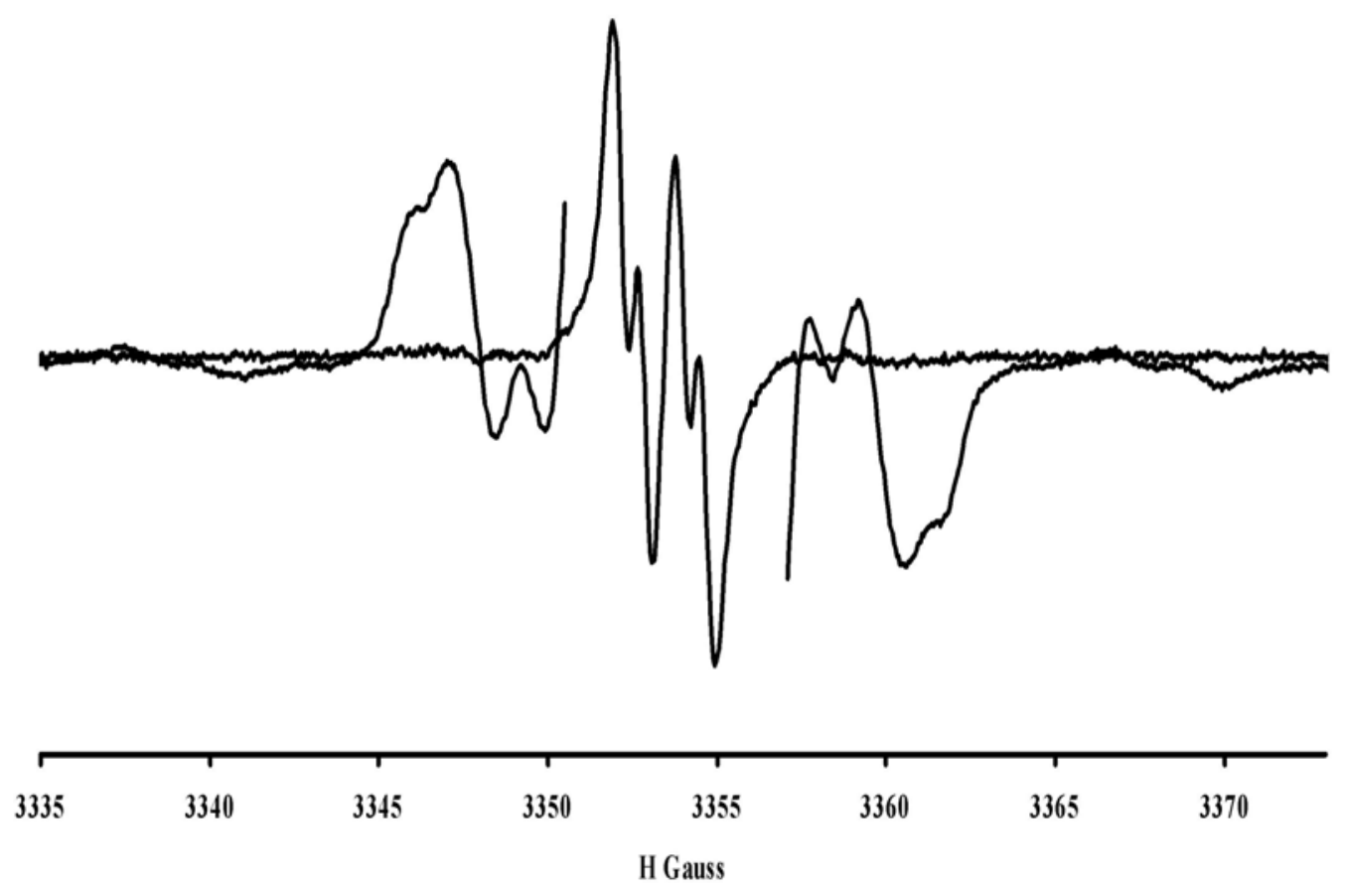

Figure 5. EPR spectra of radical 1 recorded at $220 \mathrm{~K}$.

\section{Electrochemistry and chemical switching experiments}

Cyclic voltammetric studies of radical 1 revealed two fully reversible one-electron processes, that can be assigned to the reduction of the triphenylmethyl unit to the corresponding carbanion $[\mathbf{1}]^{-}$and to the oxidation of the ferrocene unit to the ferrocenium diradical cation $\mathbf{1}^{+}$. Thus, in $\mathrm{CH}_{2} \mathrm{Cl}_{2}$, the reduction to the anion $\mathbf{1}^{-}$takes place at a potential of $-177 \mathrm{mV}$, while the oxidation to $\mathbf{1}^{+}$takes place at a potential of $+587 \mathrm{mV}$, a value that is slightly higher than that found for the unsubstituted ferrocene $(+460 \mathrm{mV})$. Therefore, these moderate potentials suggest that both ionic species are easily accessible by electrochemical oxidation (or reduction) in chronoamperometric experiments. On the other hand, these potentials are also accessible by a wide range of chemical oxidants and reductants. ${ }^{9}$ So, for example, different $\mathrm{Ag}(\mathrm{I})$ salts can be used to obtain radical 1 on a preparative scale. The progress of the reaction can be followed by absorption spectroscopy, when a solution of anion $\mathbf{1}^{-}$in THF is oxidized by controlled addition of a colorless solution of $\mathrm{AgBF}_{4}$ in the same solvent. A clean conversion to radical 1 without any by-product formation is indicated by the presence of three stable isosbestic points in the UV spectra (see Figure 4, right side). Solutions of Fe(III)- salts in THF were also used successfully to oxidize the anion $\mathbf{1}^{-}$to radical $\mathbf{1}$, although in this case the absorptions of the oxidant in the visible range complicate a direct spectro-electrochemical titration. The same applies to the strongly colored organic oxidant 
chloranil. Further chemical oxidation of radical $\mathbf{1}$ to diradical $\mathbf{1}^{+}$can also be performed successfully with an excess of $\mathrm{AgBF}_{4}$ in $\mathrm{CH}_{2} \mathrm{Cl}_{2}$ since in this solvent the $\mathrm{Ag}(\mathrm{I})$ salts are stronger oxidants than in THF. ${ }^{9}$

\begin{tabular}{|c|c|c|c|c|c|}
\hline Compound & HPTM $\mathrm{Fc}$ & $\frac{\mathrm{HO}^{-}}{{ }_{\mathrm{H}}^{+}}$PTM & $\frac{-e^{-}}{e^{-}}$ & $\mathrm{PTM}^{*} \mathrm{Fc}$ & $\frac{-\mathrm{e}^{-}}{\mathrm{e}^{-}} \mathrm{PTM}^{*}-\mathrm{Fc}^{+}$ \\
\hline & $1 \mathrm{H}$ & $1^{-}$ & 1 & & $1^{+}$ \\
\hline $\begin{array}{l}\text { External } \\
\text { stimuli } \\
\end{array}$ & & id / base & Redox & & Redox \\
\hline \multirow{2}{*}{ Properties } & Pale red & Violet & & Red-brown & Yellowish \\
\hline & Diamagnetic & Diamagnetic & & $\begin{array}{l}\text { Paramagnetic } \\
(\mathrm{S}=1 / 2)\end{array}$ & $\begin{array}{l}\text { Paramagnetic } \\
(\mathrm{S}=2 * 1 / 2)\end{array}$ \\
\hline
\end{tabular}

Figure 6. Interconversions between the different states, accessible by acid/base and redox reactions, and the distinct physical properties shown by such states.

The reduction of $\mathbf{1}^{+}$or $\mathbf{1}$ can also be easily performed chemically. For example, solutions of hydrazine are convenient reductants for ferrocenium cations. ${ }^{8 a}$ However, the most efficient and easiest way is the use of $\mathrm{K}^{+} t \mathrm{BuO}^{-}$or $(\mathrm{nBu})_{4} \mathrm{~N}^{+} \mathrm{OH}^{-}$as reducing agent. Although this may be surprising at first glance, it is well known that hydroxy- and alkoxy-anions are very effective single-electron reductants of PTM radicals. ${ }^{10}$ So, using both salts it is not only possible to reduce the ferrocenium cation group to ferrocene, but also to reduce the PTM radical group directly to the corresponding anion. Thus, a stepwise reduction of the ferrocenium diradical $\mathbf{1}^{+}$to the radical $\mathbf{1}$, and finally to the anion $\mathbf{1}^{-}$by addition of the stoichiometric amounts of a freshly prepared solution of $(\mathrm{nBu})_{4} \mathrm{~N}^{+} \mathrm{OH}^{-}$in THF was achieved successfully.

The reaction was followed by $\mathrm{UV}-\mathrm{V}$ is spectroscopy and the spectra of the intermediate radical $\mathbf{1}$ and the anion $\mathbf{1}^{-}$were found to be exactly the same as found for the pure compounds. Finally, the anion $\mathbf{1}^{-}$itself can also be converted into its precursor $\mathbf{1 H}$ by a simple addition of an acid. Such a reaction was performed by the addition of a solution of acetic acid in THF, and followed by UV-Vis spectroscopy where finally the spectrum of $\mathbf{1 H}$ was recovered, completing the full redox- and acid/base- reaction sequence described in Figure 6.

\section{Summary}

We have shown, that the four distinct species derived from radical $\mathbf{1}$ are interconvertible by means of acid/base reactions and chemical (or electrochemical) redox reactions. Because each compound exhibits different optical properties, radical $\mathbf{1}$ is an example of an electrochromic molecular device that also exhibits an intervalence band transition in the near infrared. Additionally, the different magnetic properties of radical $\mathbf{1}$ and its derivatives prove that they are indeed examples of a robust multistate/multiproperty molecular switching device. 


\section{Experimental Section}

General Procedures. Solvent THF was reagent grade from SDS, and distilled over sodium under an argon atmosphere. All reagents, organic and inorganic, were of high purity grade and obtained from E. Merck, Fluka Chemie or Aldrich Chemical Co. Elemental analyses were obtained in the "Servei de Microanalisi del CID (CSIC)", Barcelona. UV-Vis and near-IR spectra were recorded using a Varian-Cary 05E spectrophotometer. Infrared spectra were recorded on a FT-IR Perkin Elmer, and ${ }^{1} \mathrm{H}-\mathrm{NMR}$ spectra on a Bruker AC250 spectrometer. Electrochemical experiments were performed with electrochemistry equipment from EG\&G Princeton Applied Research, using a conventional three-electrode configuration with Ptelectrodes and an $\mathrm{Ag} / \mathrm{AgCl}$ electrode as the reference, with $n-\mathrm{Bu}_{4} \mathrm{NPF}_{6}\left(\mathrm{TBAPF}_{6}\right)$ as the supporting electrolyte.

\section{(E)-\{2-[4-(Bis(2,3,4,5,6-Pentachlorophenyl)methyl)-2,3,5,6-tetra-chlorophenyl]ethen-1-yl\}-}

ferrocene (1H). The preparation of compound $\mathbf{1 H}$ has been described in the literature. ${ }^{5 \mathrm{c}}$

m.p. $167-168^{\circ} \mathrm{C}$. Found: C, 39.75; H, 1.29. $\mathrm{C}_{31} \mathrm{H}_{12} \mathrm{Cl}_{14} \mathrm{Fe}$ requires $\mathrm{C}, 39.8 ; \mathrm{H}, 1.29 \%$. v $\max$ $\left(\mathrm{KBr} / \mathrm{cm}^{-1}\right)$ : 2954, 2924, 2855, 1655, 1633, 1363, 1337, 1298, 1242, 1136, 1107, 958, 809, 531,

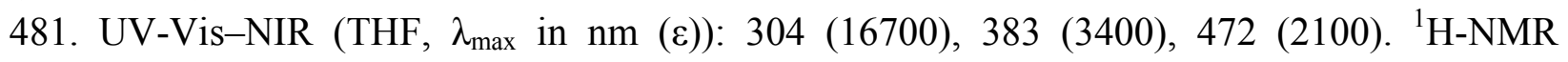
$\left(\mathrm{CDCl}_{3}\right): 4.22(5 \mathrm{H}, \mathrm{s}, \mathrm{cp}), 4.38(2 \mathrm{H}, \mathrm{s}, \mathrm{cp}), 4.52(2 \mathrm{H}, \mathrm{s}, \mathrm{cp}), 6.66(1 \mathrm{H}, \mathrm{d}, \mathrm{J}=16.6 \mathrm{~Hz}, \mathrm{vinyl}), 6.91$ (1H, d, J=16.6 Hz, vinyl), 7.03 (1H, s, methane).

[K $\left.{ }^{+}(18-C r o w n-6)\right]$ (E)-[4-[2-(Ferrocenyl)ethen-1-yl]-2,3,5,6-tetrachlorophenyl-bis(2,3,4,5,6pentachlorophenyl) methide] $\left(\mathbf{K}^{+}(18-c r o w n-6) ~[1]^{-}\right)$. Finely ground potassium hydroxide (200 mg, $3.56 \mathrm{mmol})$ and 18-crown-6 $(110 \mathrm{mg}, 0.416 \mathrm{mmol})$ were added to a solution of $\mathbf{1 H}$ (386 mg, $0.412 \mathrm{mmol}$ ) in $5 \mathrm{ml}$ of dry THF under argon atmosphere with light-exclusion. The resulting violet mixture was stirred for $16 \mathrm{~h}$. After filtration, the solvent was evaporated under reduced pressure, the crude product redissolved in $3 \mathrm{ml}$ of dry $\mathrm{CH}_{2} \mathrm{Cl}_{2}$ and re-precipitated by addition of dry $n$-hexane. The resulting solid was filtered off and recrystallized by slow diffusion of dry $n$-hexane into a solution of $\mathbf{1}^{-}$in dry $\mathrm{CH}_{2} \mathrm{Cl}_{2}$. $\mathrm{K}^{+}$(18-Crown-6) [1] crystallizes in the form of dark violet blocks, suitable for X-ray structure determination (390 mg; yield $78 \%$ ).

m.p. 216-220 ${ }^{\circ} \mathrm{C}$. Found: $\mathrm{C}, 40.05 ; \mathrm{H}, 2.70 . \mathrm{C}_{43} \mathrm{H}_{35} \mathrm{Cl}_{14} \mathrm{FeKO}_{6} \mathrm{CH}_{2} \mathrm{Cl}_{2}$ requires $\mathrm{C}$, 39.92; $\mathrm{H}$, 2.82\%. $v_{\max }\left(\mathrm{KBr} / \mathrm{cm}^{-1}\right): 2907,1628,1505,1359,1337,1105,961,835,693$. UV-Vis-NIR (THF, $\lambda_{\max }$ in $\left.\mathrm{nm}(\varepsilon)\right): 293$ (16500), 534 (35400).

Crystal data for $\mathrm{K}^{+}(18-C r o w n-6) \quad[1]^{-} \cdot \mathrm{CH}_{2} \mathrm{Cl}_{2}: \mathrm{C}_{31} \mathrm{H}_{11} \mathrm{Cl}_{14} \mathrm{Fe} \cdot \mathrm{C}_{12} \mathrm{H}_{24} \mathrm{KO}_{6} \cdot \mathrm{CH}_{2} \mathrm{Cl}_{2}, \quad M=$ 1323.89, triclinic P-1, $a=11.7772(2) \AA, b=12.5046(3) \AA, c=18.9456(5) \AA, \alpha=100.488(2)^{\mathrm{o}}, \beta$ $=90.790(2)^{\circ}, \gamma=97.939(2)^{\circ}, V=2715.02(11) \AA^{3}, T=233(2) \mathrm{K}, Z=2, \operatorname{MoK} \alpha(\lambda=0.71073 \AA)$, 10019 reflections collected, 8691 independent reflections with $\mathrm{I}>2 \sigma(\mathrm{I}), \mathrm{R} 1[\mathrm{I}>2 \sigma(\mathrm{I})]=0.0424$, $w R 2$ (all data) $=0.1059$, goodness-of-fit: 1.050 . Data were measured with a Nonius Kappa CCD and the structure was solved by direct methods (SHELXS-97) and refined by full-matrix leastsquares methods on $F^{2}$ (SHELXL-97). ${ }^{11 \mathrm{a}, \mathrm{b}}$ Crystallographic data for $\mathrm{K}^{+}(18-\mathrm{Crown}-6)[\mathbf{1}]^{-}$ reported in this paper have been deposited with the Cambridge Crystallographic Data Centre, 
CCDC 258332. Copies of this information may be obtained free of charge from The Director, CCDC, 12 Union Road, Cambridge CB2 1EZ, UK (Fax: 44-1223-336033; email: deposit@ccdc.cam.ac.uk, or www: http://www.ccdc.cam.ac.uk)

(E)-4-[2-(Ferrocenyl)ethen-1-yl]-2,3,5,6-tetrachlorophenyl-bis(2,3,4,5,6-pentachlorophenyl) methyl radical (1). $310 \mathrm{mg}(0.23 \mathrm{mmol})$ of $\mathrm{K}^{+}(18-C r o w n-6)[1]^{-}$salt were stirred with $\mathrm{AgBF}_{4}$ (40 mg, $0.24 \mathrm{mmol})$ in dry THF $(5 \mathrm{ml})$ for $2 \mathrm{~h}$ at room temperature. The dark brown solution was filtered, reduced in volume and redissolved in $n$-hexane. Chromatography on a silica column with $n$-hexane yielded $190 \mathrm{mg}(80 \%)$ of $\mathbf{1}$ as a dark brown powder. Analytical data are identical with those already reported in the literature. ${ }^{5 \mathrm{c}} \mathrm{m} . \mathrm{p} .136-140{ }^{\circ} \mathrm{C}$. Found: C, 39.7; H, 1.18. $\mathrm{C}_{31} \mathrm{H}_{11} \mathrm{Cl}_{14} \mathrm{Fe}$ requires $\mathrm{C}, 39.70 ; \mathrm{H}, 1.2 . v_{\max }\left(\mathrm{KBr} / \mathrm{cm}^{-1}\right): 2923,2852,1624,1508,1458,1336$, 1299, 1259, 817, UV-Vis-NIR (THF, $\lambda_{\max }$ in nm ( $)$ )): 290 (1400), 386 (25500), 444 (11500), 570 (2100), 638 (1800), 970 (1300). electrochemistry $\left[\mathrm{CH}_{2} \mathrm{Cl}_{2}, 0.1 M \mathrm{TBAPF}_{6}, \mathrm{Ag} / \mathrm{AgCl}\right]$ : oxidation: $587 \mathrm{mV}$, reduction: $-177 \mathrm{mV}$.

[(E)-4-[2-(Ferrocenium)ethen-1-yl]-2,3,5,6-tetrachlorophenyl-bis-(2,3,4,5,6-pentachlorophenyl)methyl radical] $\mathbf{B F}_{4}[1]^{+}$. Radical $1(20 \mathrm{mg}, 21 \mu \mathrm{mol})$ and $\mathrm{AgBF}_{4}(10 \mathrm{mg}, 50 \mu \mathrm{mol})$ were stirred for 16 hours in dry $\mathrm{CH}_{2} \mathrm{Cl}_{2}(5 \mathrm{~mL})$. The gray precipitate $(\mathrm{Ag})$ formed during the oxidation was filtered off, the solution reduced in volume to approx. $2 \mathrm{~mL}$ and [1] ${ }^{+} \mathbf{B F}_{4}{ }^{-}$precipitated on addition of dry $n$-hexane ( approx. $20 \mathrm{~mL}$ ). The dark brown solid was washed with $n$-hexane and dried. m.p.: $>300^{\circ} \mathrm{C}$. Found: $\mathrm{C}, 39.91 ; \mathrm{H}, 2.11 . \mathrm{C}_{31} \mathrm{H}_{11} \mathrm{Cl}_{14} \mathrm{Fe}^{\circ} \mathrm{BF}_{4} \mathrm{C}_{6} \mathrm{H}_{14}$ requires $\mathrm{C}, 40.09 ; \mathrm{H}$, $2.27 \%$. $v_{\max }\left(\mathrm{KBr} / \mathrm{cm}^{-1}\right): 2924,2853,1631,1465,1379,1337,1262,1242,1119,1057,818$. UV-Vis-NIR (THF, $\lambda_{\max }$ in nm, ( $\left.(\varepsilon)\right): 386$ (25000), 564 (1200).

\section{Acknowledgments}

We thank the Programa Nacional de Materiales, under project NanoMultiFun (MAT2003-04699) and DGR, Catalunya (2001SGR00362), Catalan Network CERMAE and Acción Integrada Hispano-Austríaca (HU-2002-0046). C.S. thanks the FWF Vienna for a postdoctoral grant (Erwin-Schrödinger Stipendium J2103).

\section{References}

1. (a) Ventosa, N.; Ruiz, D.; Rovira, C.; Veciana J. J. Mol. Crys. Liq. Cryst. 1993, 232, 333. (b) Ballester, M. Adv. Phys. Org. Chem. 1989, 25, 267. (c) Armet, O.; Veciana, J. Rovira, C.; Riera, J.; Castañer, J.; Molins, E.; Rius, J.; Miravitlles, C.; Olivella, S.; Brichfeus, J.; J. Phys. Chem. 1987, 91, 5608. (d) Ballester, M.; Pascual, I.; Riera, J.; Castañer, J. J. Org. Chem. 1991, 56, 217. (e) Domingo, V. M.; Castañer, J. Chem. Comun 1995, 895.

2. (a) Veciana, J.; Rovira, C.; Ventosa, N.; Crespo, M. I.; Palacio, F. J. Am. Chem. Soc. 1993, 115, 57. (b) Maspoch, D.; Ruiz-Molina, D.; Wurst, K.; Domingo, N.; Cavallini, M.; 
Biscarini, F.; Tejada, J.; Rovira, C.; Veciana, J. Nature Materials 2003, 2, 190. (c) Vasilevsky, S. F.; Tretyakov, E. V.; Ikorskii, V. N.; Romanenko, G. V.; Fokin, S. V.; Shwedenkov, Y. G.; Ovcharenko, V. I. ARKIVOC 2001, (ix), 55.

3. (a) Ratera, I.; Ruiz-Molina, D.; Sporer, C.; Marcén, S.; Montant, S.; Létard, J.-F.; Freysz, E.; Rovira, C.; Veciana, J. Polyhedron 2003, 22, 1851. (b) Ratera, I.; Létard, J.-F.; Marcén, S.; Ruiz-Molina, D.; Freysz, E.; Rovira, C.; Veciana, J. Chem. Phys Lett. 2002, 363, 245.

4. See, for example: (a) Molecular Switches, Feringa, B. L. Ed.; Wiley-VCH: Weinheim, New York, 2001. (b) Raymo, F. M. Adv. Mater. 2002, 14, No. 6, 401. (c) Photochromism: Memories and Switches, Irie, M. Ed Chem. Rev. 2000, 100, 1683. (d) Itkis, M. E.; Chi, X.; Cordes, A. W.; Haddon, R. C. Science 2002, 296, 1443. (e) Miller, J. S.; Angew. Chem. Int. Ed. 2003, 42, 27. (f) Rurack, K.; Bricks, J. L. ARKIVOC 2001, (xi), 31.

5. (a) Ratera, I.; Ruiz-Molina, D.; Renz, F.; Ensling, J.; Wurst, K.; Rovira, C.; Gütlich, P.; Veciana, J. J. Am. Chem. Soc. 2003, 1462. (b) Elsner, O.; Ruiz-Molina, D.; Ratera, I.; VidalGancedo, J.; Rovira, C.; Veciana, J. J. Organomet. Chem. 2001, 637, 251. (c) Elsner, O.; Ruiz-Molina, D.; Vidal-Gancedo, J.; Rovira, C.; Veciana, J. Chem., Commun. 1999, 579.

6. (a) Sporer, C.; Ratera, I.; Ruiz-Molina, D.; Zhao, Y.; Vidal-Gancedo, J.; Wurst, K.; Jaitner, P.; Clays, K.; Persoons, A.; Rovira, C.; Veciana, J. Angew.Chem., Int. Ed. 2004, 43, 5266. (b) Sporer, C.; Ratera, I.; Ruiz-Molina, D.; Vidal Gancedo, J.; Wurst, K.; Jaitner, P.; Rovira, C.; Veciana, J. J. Phys. Chem. Solids 2004, 65, 753.

7. (a) Ratera, I.; Ruiz-Molina, D.; Vidal-Gancedo, J.; Novoa, J. J.; Wurst, K.; Letard, J. F.; Rovira, C.; Veciana, J. Chem. Eur. J. 2004, 10, 603. (b) Ratera, I.; Ruiz-Molina, D.; VidalGancedo, J.; Wurst, K.; Daro, N.; Létard, J.-F.; Rovira, C.; Veciana, J. Angew.Chem. Int. Ed. 2001, 40, 919. (c) Ratera, I.; Ruiz-Molina, D.; Sánchez, C.; Alcalá, R.; Rovira, C.; Veciana, J. Synthetic Met. 2001, 121, 1834.

8. Examples of electrochemical switching of non-linear optical properties have already been reported: (a) Malaun, M.; Reeves, Z. R.; Paul, R. L.; Jeffery, J. C.; McCleverty, J. A.; Ward, M. D.; Asselberghs, I.; Clays, K.; Persoons, A. Chem. Commun. 2001, 49. (b) Coe, B. J. Chem. Eur. J. 1999, 5, 2464.

9. Connelly, N. G.; Geiger, W. E. Chem. Rev. 1996, 96, 877.

10. Ballester, M.; Pascual, I. J. Org. Chem. 1991, 56, 841.

11. (a) Sheldrick, G. M. SHELXS-97 program for crystal structure solutions, Göttingen, 1997.

(b) Sheldrick, G. M. SHELXL-97 program for refinement of crystal structures, Göttingen, 1997. 